\title{
Caregiving, Family Burden and Medication Adherence
}

\author{
E. Ennis, C. Corry \\ School of Psychology, University of Ulster, Londonderry, Northern Ireland \\ Email: e.ennis@ulster.ac.uk
}

Received October 28, 2013; revised November 28, 2013; accepted December 5, 2013

Copyright (C) 2014 E. Ennis, C. Corry. This is an open access article distributed under the Creative Commons Attribution License, which permits unrestricted use, distribution, and reproduction in any medium, provided the original work is properly cited. In accordance of the Creative Commons Attribution License all Copyrights (c) 2014 are reserved for SCIRP and the owner of the intellectual property E. Ennis, C. Corry. All Copyright (C) 2014 are guarded by law and by SCIRP as a guardian.

\begin{abstract}
Caregivers are an essential component of any community. Advances in medicalcare have brought about an increasing population which is reliant on care, and communities deal with most of the burdens and practicalities of public health issues. In order to provide efficient support services, we need to know the challenges of caregivers so that we can address what types of support they require. The current study examines whether those who have a mental health difficulty and are either engaged in caregiving duties or perceive family burden may be less adherent to their medications in comparison with those who also have a mental health difficulty but do not perceive family burden or perform caregiving. Data used was from the National Comorbidity Study Replication (NCS-R), which examines the mental health profile of the American population. The group examined were those who received the family burden interview, and indicated that they were taking a prescription medication for a mental health difficulty under the supervision of a health professional $(N=489)$. Zero inflated Poisson regression showed that caregiving/family burden was unrelated to adherence to supervised prescription medicines for mental health difficulties, regardless of the kinship of who was ill, or the nature of their illness (physical versus mental). Adherence to prescription medications for mental health difficulties does not appear to be one of the challenges faced by this group. Findings are discussed in terms of the economic and moral importance of health professionals identifying and understanding the challenges experienced by caregivers/those reporting family burden. This is necessary so that appropriate interventions and support services can be targeted, and further research plays an important role in achieving this objective.
\end{abstract}

\section{KEYWORDS}

Medication Adherence; Mental Health; Family Burden; Caregiving

\section{Introduction}

Family burden refers to "all the difficulties and challenges experienced by families as a consequence of someone's illness" [1]. It is conceptualised as a negative experience (practical and/or emotional challenges [1]. As it may solely be an emotional experience, it may or may not involve actual caregiving [1]. Caregiving on the other hand involves the provision of practical assistance such as help with personal care, medication management, activities of daily living, or financial management [2]. This practical experience may or may not be perceived as an emotional burden.

The caregiver role can involve challenges and adversities such as negative effects on physical and mental health, functional capacity, cognition, and life satisfac- tion, as well as negative repercussions on professional, family and marital roles and daily activities [3-6]. However, it can also involve rewards such as role satisfaction, mutual love and respect, maintaining dignity [6-8]. The physical and emotional experience of the caregiver role can be mediated by gender, age, income and low perceived social support, individual differences in perceived stress and methods of coping, and the exact demands /burden [3-6,9].

The current study examines whether family burden/ caregiving may represent a vulnerability to non-adherence to medications for mental health difficulties. Adherence ${ }^{1}$ is

\footnotetext{
${ }^{1}$ The current paper consciously uses the term "adherence” rather than "compliance" in recognition of the well accepted importance of the interaction between the health professional and the layperson.
} 
"the extent to which a patient's behavior coincides with medical or prescribed health advice” [10]. It averages only 50\% among patients suffering chronic diseases (physical or mental) [10]. As a widespread major obstacle to treatment effectiveness, patient quality of life, and a burden and demand on the health care system and the family, health professionals need to understand and address the dynamics of adherence, or the lack thereof [11].

Theoretical models concerning medication adherencesee the issue as based on social and cognitive factors, with influences spanning the illness and its medication /treatment regime, the person/patient himself/herself, and the interactions between the health care provider and the patient $[11,12]$. Efforts to address these factors do yield increases in medication adherence in some studies [11, 13,14]. However, effective interventions to increase adherence are individualized, long-term, complex multilayered matters and many meet with limited success [11, $13,14]$. Using relevant theoretical frameworks to guide us towards an understanding of the factors associated with adherence versus non adherence, is essential to enhancing our understanding of the matter, identifying groups with elevated vulnerability to non-adherence and subsequently developing effective interventions to reduce the problem [15].

Caregivers are an essential component of any community as advances in medical care have brought about an increasing population which is reliant on care, and communities deal with most of the burdens and practicalities of public health issues $[3,5,9,16]$. Scientific research needs to examine population based public health outcomes of caregivers, and provide foundations to inform policies and interventions to support caregivers [9]. "Caring per se does not lead to depressive symptoms, health problems and social isolation unless it is accompanied by cohabitation, insufficient income to meet basic needs and a lack of formal support services" [17]. In order to provide efficient support services, we need to know the challenges of caregivers so that we can address what types of support they require.

It has been suggested that the ability to adhere to their own medications may represent one of the challenges faced by caregivers. Caregivers are said to be more likely than non-caregivers to not adhere to their medication, to forget their own medication than that of their care recipient, and to sacrifice their own medication rather than that of their care recipient if financial restrictions were in place, particularly if the care recipient had complex medication needs [18]. Considerable methodological factors are acknowledged, but it is tentatively suggested that the emotional and financial barriers associated with caregiving may lead individuals to pay less attention to the needs of their own health [18]. This suggested appraisal of the needs of their care recipient as more important than their own and/or an ability to cope with the demands of two medication regimes, aligns with the importance of appraisal and coping within Leventhal's model of adherence. These same reasons align with the motivation (patients must be motivated to carry out their own treatment recommendations) and strategy (patients need a workable strategy for following treatment recommendations and overcoming barriers) components of the Information/ Motivation/Strategy (IMS) model of adherence, which is built on earlier models such as the Health Belief Model and the Theory of Planned behavior [11].

This possible reduced adherence is concerning as caregivers actually show poorer health (physical and mental) in comparison with non-caregivers, with more intense caregiving duties bringing greater risk [3-5,9,19,20]. Health and wellbeing are of critical importance, but particularly amongst caregivers as physical and mental health within caregivers substantially improves the quality of life of the care recipient, with the chief risk of reduced quality care or institutionalization being a decline in the health of family caregivers themselves rather than a decline in the health of care recipients [3,9,21,22]. The study will focus on those who report caregiving duties or family burden, but more specifically the current research focuses on those caregivers who also meet the criteria for a mental health difficulty.

This is because this above group may be particularly vulnerable as mental health difficulties in themselves also represent a common barrier to successful adherence [11]. Furthermore, mental health and wellbeing appear to be particularly important among caregivers as their depressive symptoms relate more closely to the quality of care they provide and their own health problems, than do the objective stressors that are inherent in the care they provide [22]. Depressed individuals are less likely to perceive positive aspects of caregiving due to their focus on negative aspects of themselves and their daily experience, and thus are at higher risk of burden $[4,19]$. Overall, the current study examines the hypothesis that those who have a mental health difficulty and are either engaged in caregiving duties or perceive family burden may be less adherent to their medications in comparison with those who also have a mental health difficulty but do not perceive family burden or perform caregiving.

In examining the relationship between family burden/ caregiving and adherence to medications for mental health difficulties, evidence would suggest that it is also important to consider the nature of the relationship between the individuals (kinship) and also the nature of the illness experienced by the individual they are providing care for (physical versus mental health difficulty) [9]. Concerning kinship, burden appears greater when caring for spouses and children in comparison with caring for 
elderly parents or siblings $[3,6,16,23]$. Concerning the nature of the illness, having a relative or being a caregiver to someone with an alcohol, drug or mental health difficulty is associated with more burden, stigma and embarrassment in comparison with having a relative or being a caregiver to someone with a physical health difficulty [6,24-26]. Furthermore, this did not appear to be a direct function of burden as the highest burden was reported by the group with both physical and alcohol/ drug/ mental health difficulties in the family $[25,26]$. Overall, different caregivers may have different needs and struggles or vulnerabilities depending on their own profile and that of their care recipient, and thus may benefit from different interventions $[9,19,23]$.

To conclude, the objective of this paper is to examine whether those who have a mental health difficulty and are either engaged in caregiving duties or perceive family burden may be less adherent to the medications for their mental health difficulties in comparison with those who also have a mental health difficulty but do not perceive family burden or perform caregiving. To achieve this, the NCSR will be used, which is an examination of the mental health profile of the American population, using a large representative random sample. "A better understanding of populations at greater risk of non-adherence, and possible barriers to the appropriate medication use, can offer targets for future interventions" [18]. Supporting caregivers in their roles is essential given their economic importance within society in that they save the healthcare system vast amounts of money [18].

\section{Methodology}

A full report of the methods employed within the NCS-R can be found Kessler et al. (2004) [27]. The Human Subjects Committees of both Harvard Medical School (HMS) and the University of Michigan approved the recruitment, consent, and field procedures of the NCS-R [27]. These ethical guidelines are compliant with the Helsinki Declaration on ethical principles for medical research involving human subjects.

\section{Samples}

The overall NCS-R sample consisted of 9282 individuals. However, the measures concerning family burden were only administered to a random 30\% subsample [27]. Within this subsample who received the family burden interview ( $\mathrm{N}=3192), 489$ individuals indicated that they were taking a medication for a mental health difficulty under the supervision of a health professional. As adherence to medications for mental health difficulties was a core variable within the current study, this smaller subsample of those who are taking medications for a mental health difficulty under the supervision of a health profes- sional ( $\mathrm{N}=489$; 137 males and 352 females) will be focused upon and shall be referred to as the medication group within the current paper. Their ages ranged from 18 - 93 years old, with the mean age being 49.63 years old ( $\mathrm{SD}=16.44), 49$ years old being the median age, and 50 and 52 years old being the modal ages.

The medication group differed significantly from the remainder of the sample (those who got the family burden interview but did not report taking a prescription medication for a mental health difficulty under the supervision of a health professional, $\mathrm{N}=2703$ ) in terms of both sex $\left(\chi^{2}(1)=52.27, p<0.001\right)$ and age $(t(726.72)=$ $-5.04, p<0.001)$. The medication group had a higher than expected proportion of females and an older average age (see Table 1). For this reason, sex and age will be included within analyses. Demographics are compared to the subsample who received the family burden interview as opposed to the overall NCS-R sample, as it was a random 30\% who got the family burden interview there is no reason to suspect that they should be different from the overall NCSR sample [27]. These preliminary analyses were conducted to assess which demographic factors might be important to consider in subsequent analyses. However, as was noted above, the research in this paper focuses exclusively on the medication group as these were the only individuals assessed concerning their family burden/caregiving and their adherence to prescription medications for mental health difficulties.

\section{Materials}

\subsection{Pharmacoepidemiology}

Medication use and adherence were assessed within the pharmacoepidemiology section of the NCS-R. Participants were asked whether they took any prescription medicine in the past 12 months for problems with their with their emotions, nerves, their use of alcohol or drugs, energy, concentration, sleep, or ability to cope with stress, whether or not these medications were under the supervision of a health professional, and whether or not they adhered to these medications. Within this paper, these difficulties are referred to under the umbrella term of 'mental health difficulties'.

Table 1. Comparison demographics for medication group versus non medication group.

\begin{tabular}{|c|c|c|}
\hline & $\begin{array}{l}\text { Medication group } \\
\qquad(\mathrm{N}=489)\end{array}$ & $\begin{array}{l}\text { Non-medication group } \\
\qquad(\mathrm{N}=2703)\end{array}$ \\
\hline Sex: male & $\begin{array}{c}\text { 4.3\% (Obs) versus } \\
\text { 6.58\% (Exp) }\end{array}$ & $\begin{array}{c}38.7 \% \text { (Obs) versus } \\
36.72 \% \text { (Exp ) }\end{array}$ \\
\hline Sex: female & $\begin{array}{l}\text { 11\% (Obs) versus } \\
\text { 8.74\% (Exp) }\end{array}$ & $\begin{array}{c}\text { 46\% (Obs) versus } \\
\text { 48.31\% (Exp) }\end{array}$ \\
\hline Age & $\begin{array}{c}M=49.63 \text { years old } \\
(S D=16.44)\end{array}$ & $\begin{array}{c}M=45.49 \text { years old } \\
(S D=18.37)\end{array}$ \\
\hline
\end{tabular}

Key: Obs = observed frequencies, Exp = expected frequencies. 
Only those who indicated that their medication consumption was under the supervision of their health professional were interviewed in detail concerning their adherence to three medications ${ }^{2}$. Specifically, "People do not always take their medication as they are supposed to. Think of a typical month when you took (medication) in the past 12 months. How many days out of 30 did you typically either forget to take it or take less of it than you were supposed to take?” Pearson's correlation coefficient showed a strong correlation coefficient between the measures of adherence to each of the three medications ( $r$ $=0.51, r=0.52, r=0.72$, all $\underline{p}<0.001)$. Although there is variation in the strength of these correlation coefficients, all are statistically significant. This is therefore taken as suggesting that non-adherence to one medication was accompanied by similar degrees of non-adherence to other medications, and thus only the first measure of adherence will be used as an overall measure of adherence. All individuals within this subgroup had an adherence score, which could range between 0 and 30 depending on the number of days within the month that they reported forgetting to take their medication. A score of 0 therefore indicated perfect adherence.

\subsection{Family Burden}

Family burden was assessed within section 42 of the NCS-R. The instrument used to assess family burden was constructed for the purposes of the World Mental Health study, and considered elements of both objective (practical) and subjective (emotional) burden. No details of the psychometrics of the questionnaire are available. However, the NCS-R information allows examination of both experiences (family burden and caregiving) as it asks how individuals feel about the health of their family, and also what practical duties they perform.

Participants were asked a series of questions concerning their close family members (parents, siblings, children, spouse/partner), and the health problems of these individuals in terms of 12 illnesses. The list included both physical illnesses (cancer, serious heart problems, permanent physical disability such as blindness or paralysis, or any other serious chronic physical illness) as well as mental illnesses (serious mental problems like senility or dementia, mental retardation, schizophrenia or psychosis, manic depression, or any other serious chronic

\footnotetext{
${ }^{2}$ It is acknowledged that these "three medications" may be different for different people and adherence to medication may vary as function of whether the medication is perceived as important or providing them with relief from complaints as opposed to limiting future risks for health outcomes. However, all medications reported in this section would be for the treatment of mental health difficulties as opposed to physical health difficulties (although their function may be to address a physical issue that is a secondary symptom of a primary mental health difficulty).
}

mental problem). These were all included within the mental health category given their inclusion in DSM-IV. Participants responded indicating which of their kin experienced each condition. Only if a participant indicated that any of their first degree relatives had any of the above conditions were they then asked about family burden. This was indicated through a question in which participants rated the extent to which their own life was affected by the health problems of their relative. This was recoded as a dichotomous variable with those who reported that the health of their relative impacted upon their life "a lot" or "some" deemed as experiencing family burden, as opposed to those who responded as "a little” or "not at all”. Only those who reported burden were asked about the tasks they performed.

Within the current study, an overall variable ("illness and impact") was created to summarise the relatives health profile (presence versus absence of illness) and the extent to which it impacts on an individual's life (perceived family burden or not, and practical caregiving or not (the provision of help with practical tasks such as washing, getting around or housework, or spending more time keeping company or financial support). Specifically, individuals were grouped as 1) those who had no health difficulties within their family health profile, 2) those who did have health difficulties within their family health profile but did not consider these a burden, 3) those who did have health difficulties within their relatives health profile and did consider them a burden but did not perform any practical caregiving duties, and 4) those who did have health difficulties within their relatives health profile and did consider them a burden and did perform any practical caregiving duties. Group three are considered to represent a family burden group due to their perceiving emotional consequences but not reporting any practical activities, whilst group four are considered to represent that caregiver group due to their burden and practical duties ${ }^{3}$. Within this variable no consideration was taken of kinship or whether the illness was physical or mental in nature.

For alternative analysis purposes in terms of considering kinship, information was coded as there being illness within the family of origin (parents or siblings), the created family (children or spouse/partner) or illnesses within both families. Within this variable concerning kinship, no account was taken of whether the illnesses were physical or mental, perceived as a burden or not, and involved any caregiving or not. To consider nature of the illness, a separate variable was constructed using the cri-

\footnotetext{
${ }^{3}$ It is recognised that many people in the world may perform similar caregiving duties but not perceive them as a burden. However, such individuals cannot be identified from the NCSR as only those who indicated that they perceived family burden were questioned concerning the duties they perform.
} 
teria outlined above to determine whether the family health profile consisted of only physical illnesses, only mental illnesses or a combination of both physical and mental illnesses. Within this variable, no consideration was taken of kinship, burden or caregiving. It was necessary to keep groups exclusive regarding impact, kinship and the physical/mental health distinction in order to keep group sizes as large as possible within the analyses.

\subsection{Analyses}

Zero inflated Poisson regression was deemed as the appropriate statistical technique given that the dependent variable for this section of the analyses (medication adherence) was count data. This also allowed medication adherence to be examined as a continuous variable as opposed to dichotomous absent or present. This was conducted within the MPlus statistical package as descriptive statistics had shown that the dependent variable (medication adherence) was zero inflated. MPlus also allowed incorporation of the appropriate weights and stratification variables.

\section{Results}

\subsection{Descriptive Statistics}

As was noted earlier, 489 individuals received the family burden interview and indicated that they were taking a prescription medication for a mental health difficulty under the supervision of a health professional. Of these, 261 individuals reported perfect medication adherence (missed zero days) whilst the remaining 156 individuals reported non adherence varying from missing 1 day to missing 30 days. Information was missing for 72 individuals and the mean adherence score was 2.81 days (SD $=6.82$ ). This indicates that 2.81 was the average number of days of missed medication. Table 2 illustrates the descriptors for the sample in terms of illness, burden and caregiving, types of health complaints amongst relatives and kinship and illness.

\subsection{Analyses of Predictors of Adherence}

A zero inflated Poisson regression was used to examine the predictors of medication adherence (days missed from medication) in terms of family illness and impact, nature of health difficulties and kinship of health difficulties, within the context of controlling for other predictors such as sex and age (Table 2). As is standard practice, results are interpreted in terms of the regression coefficient, the standard error of the regression coefficient and the ratio of these two indices to each other to yield a $\mathrm{z}$ statistic. As the $\mathrm{z}$ statistic follows the properties of a normal distribution, indices either above 1.96 or below -1.96 would indicate statistical significance at the
Table 2. Poisson regression assessing predictors of medication adherence ${ }^{4}$.

\begin{tabular}{|c|c|c|c|c|}
\hline & \multirow[t]{2}{*}{$\begin{array}{l}\text { Descriptive } \\
\text { statistics }\end{array}$} & \multicolumn{3}{|c|}{$\begin{array}{l}\text { Zero inflated Poisson } \\
\text { regression model }\end{array}$} \\
\hline & & Coeff & $\mathrm{SE}$ & Est/SE (Z) \\
\hline Sex (ref=male) & & 0.01 & 0.29 & 0.05 \\
\hline Age (centered on mean) & & 0.01 & 0.01 & 1.73 \\
\hline $\begin{array}{l}\text { Family illness and impact } \\
\text { (ref = no illness within family) }\end{array}$ & $160(32.7 \%)$ & & & \\
\hline $\begin{array}{l}\text { Illness but no } \\
\text { perceived burden }\end{array}$ & $184(37.6 \%)$ & -0.51 & 1.31 & -0.45 \\
\hline $\begin{array}{l}\text { Illness and burden but } \\
\text { no practical caregiving }\end{array}$ & $54(11 \%)$ & 0.34 & 1.18 & 0.29 \\
\hline $\begin{array}{l}\text { Illness and burden and } \\
\text { practical caregiving }\end{array}$ & 85 (17.4\%) & -0.53 & 1.15 & -0.46 \\
\hline $\begin{array}{l}\text { Type of health problem } \\
\text { (ref-no health problems) }\end{array}$ & $161(32.9 \%)$ & & & \\
\hline $\begin{array}{l}\text { Only physical health } \\
\text { problems in family }\end{array}$ & $73(14.9 \%)$ & -0.32 & 1.20 & -0.27 \\
\hline $\begin{array}{l}\text { Only mental health } \\
\text { problems in family }\end{array}$ & $107(21.9 \%)$ & -0.29 & 1.12 & -0.26 \\
\hline $\begin{array}{l}\text { Physical and mental health } \\
\text { problems in family }\end{array}$ & $148(30.3 \%)$ & -0.46 & 1.15 & -0.40 \\
\hline $\begin{array}{l}\text { Which relative is ill } \\
\text { (ref = no illness in family) }\end{array}$ & 184(37.6\%) & & & \\
\hline $\begin{array}{l}\text { Only illness in } \\
\text { family of origin }\end{array}$ & $200(40.9 \%)$ & 0.73 & 0.58 & 1.27 \\
\hline $\begin{array}{l}\text { Only illness in } \\
\text { created family }\end{array}$ & $44(9.0 \%)$ & 0.77 & 0.69 & 1.12 \\
\hline $\begin{array}{l}\text { Illness in both origin } \\
\text { and created family }\end{array}$ & $61(12.5 \%)$ & 0.77 & 0.64 & 1.20 \\
\hline
\end{tabular}

$\mathrm{p}<0.05$ level. This was not the case within any of the current analyses. This is led to concluding that contrary to our hypothesis, none of the specified variables (sex, age, illness and impact, kinship of family illness or nature of family illness) predicted adherence to supervised prescription medications for mental health difficulties i.e. days of missed medication. Neither those who had illness within their family but perceived no burden, those who had illness in their family but performed no practical caregiving, nor those who had illness within their family and did perceive this as a burden and also performed caregiving differed significantly from those who had no illness within their family in terms of adherence to their own supervised prescription medications for mental health difficulties (Table 2). When nature of illness was considered, neither those who only had physical illnesses within their family, those who only had mental illnesses

\footnotetext{
${ }^{4}$ The proportion of individuals within the "no health problems within the family" category varies slightly in terms of the percentage of cases that it occupies. This is due to slightly different proportions of missing data across the various sections of information (i.e. who is ill, what duties are done etc.).
} 
within their families, nor those who had both physical and mental illnesses within their family differed significantly from those who had no illness within their family in terms of adherence to their own supervised prescription medications for mental health difficulties (Table 2). When kinship of illness was considered, neither those who only had illnesses within their family of origin, those who only had illnesses within their created family, nor those who had illnesses in both their family of origin and their created family differed significantly from those who had no illness within their family in terms of adherence to their own supervised prescription medications for mental health difficulties (Table 2). Neither sex nor age specifically predicted adherence either.

\section{Discussion}

The current results show that contrary to our hypothesis, neither family burden, caregiving duties, nature of health difficulties within the family nor kinship of illnesses appear to relate to adherence to one's own medications for mental health difficulties. This is important information in that family burden and caregiving are associated with many challenges and adversities, and these groups require support in order to overcome these [3-6,9,18]. The protection of those who experience family burden and caregiving is essential given the extent of the services they provide to the community $[3,5,9,16]$, and the impact of their mental health and wellbeing on their ability to provide these services $[3,9,21,22]$. However, it would appear that adherence to medications for their own mental health difficulties is not a domain that this group experience challenges with, thus support interventions should be focused elsewhere. This finding appeared consistent across the group despite suggestions that the kinship of the illness and the nature of the illness of the care recipient influenced the caregiving experience $[3,6,9,16$, 23-26]. Although it was suggested that different caregivers may have different needs and struggles or vulnerabilities depending on their own profile and that of their care recipient, and thus may benefit from different interventions [9,19,23], this differentiation across groups does not appear to apply to medication adherence.

The current results only apply to medication adherence for mental health difficulties as opposed to physical health difficulties, but they appear to reject the suggestion that caregiving may represent a vulnerability to nonadherence to prescription medicines [18]. This is important in that the initial results of Shrank et al. suggested that caregivers may represent a group towards which may require extra attention within interventions to enhance adherence, and we had suggested that this vulnerability might be further confounded for those individuals who either perform caregiving duties or perceive family burden and also have a mental health difficulty themselves for which they are taking supervised prescription medications. The initial authors (Shrank et al.) acknowledged several methodological factors within their research in that their sample was not representative of the entire population, and both sampling and reporting biases may have exerted influences [18]. Their research also categorized those who care for healthy children as caregivers. The current findings suggest that these methodological limitations did have quite an effect.

Several methodological factors must be noted in interpreting the current results. Whilst the NCS-R provides information on whether or not the individual performs caregiver tasks, this information is only available for those who indicate that they feel burdened by the health of their relatives. Those who indicate that they did not perceive themselves to be burdened were filtered out and not asked the task questions. It is quite likely that there are many people who perform carer tasks but do not perceive them as a burden and rather accept these as part of their daily routine. Therefore, whilst the current findings can be said to generalize, they only generalize to burdened caregivers. It could however be reasonably suggested that it is most likely to be the burdened caregivers who are most vulnerable to non-adherence in comparison with the non-burdened caregivers.

This aligns with the urgent concern of understanding the underlying perception of family burden, and whether or not this equates to actual caregiving. As was noted above, it seems reasonable to suggest that certain individuals perform duties and see this as part of their routine, whereas other individuals may be performing comparable duties and perceive this as impacting upon their life. Further examination is required in terms of of the process of self-identifying as a caregiver, and what family burden is due to: is it worries about the relative (the "family effect"), or direct instrumental caregiving (the "caregiver effect") [28]? This may even vary across different cultural settings as variations in supports available and cultural expectations influence the caregiving experience.

Within the NCS-R, an initial general question is posed concerning burden and after this, the current study focused on the questions concerning provision of practical caregiving (often referred to as objective burden). Other researchers have noted the importance of considering the various types of burden, namely relationship burden (extent to which care recipients behavior is perceived by caregiver to be manipulative or overly demanding), stress burden (perceived effects of caregiving on affect) and objective burden (extent to which care relationships impose on observable aspects of caregivers life) [21]. Questions were asked within the NCS-R concerning emotional or subjective burden such as worry or embarrassment, but were not included in the current analyses due to a 
high incidence of missing data.

As noted briefly above, details of any caregiving relationship situations are not available in terms of the physical health of the caregiver themselves recipient, whether or not they co-reside, whether or not they are the primary caregiver, the number of hours invested in caregiving duties, impact of different familial relationships (parent/ sibling/spouse/offspring) etc. Furthermore, in most cases individuals had more than one ill relative within their family health profile, and where the burden or duties stemmed from was not apparent. An individual might have several ill relatives, but only feel burdened or provide care in relation to one individual illness. Co-residency typically brings high levels of excessive burden, depression, social isolation, and poor state of health, which is primarily generated by the greater daily frequency of the care and the greater commitment to maintain the person in the residence [3]. Some of these elements (e.g. time investment and financial implications of family burden/caregiving) are available within the NCS$\mathrm{R}$ but have a high incidence of missing data. Also, the current study simply provides a one point in time picture. Longitudinal research is definitely warranted in terms of the changing emotions and needs associated with different stages of an illness [6]. Further research to examine population based public health outcomes of caregivers, and provides foundations to inform policies and interventions to support caregivers is a definite area of need [9].

Individualswere only questioned concerning their adherence to medications which they were taking in the past 12 months for problems with their emotions, substance use, energy, concentration, sleep, or ability to cope with stress. Whether or not adherence to medications for other physical health problems may differ from adherence to the above medications for emotion related issues is unknown. The issues concerning self-report measures of adherence must also be acknowledged. Some evidence suggests that interview based self-reports of medication adherence are not concordant with electronic measures of actual adherence [29]. However, such measures have been used in scientific research in peer reviewed academic journals [30]. Also, reviews conclude that asking patients about their medication taking behavior is an efficient method of assessing adherence, so long as it is conducted in a non-judgmental manner [11, 15]. They also note that both direct and indirect measures of adherence measurement have advantages and disadvantages, and no one method should be considered as the "gold standard" [15].

\section{Conclusion}

Limitations and suggestions for future research have been outlined above, however the results of the current study provide very valuable information, and possess the great strength that they come from a random and representative sample of the American population. Further research is definitely warranted on the dynamics underlying medication adherence, or the lack thereof. However, the main focus of the current study was to identify whether or not the ability to adhere to their own mental health medications is a challenge faced by caregivers/ those who perceive family burden. However the current research suggests that whilst many stresses may be experienced by caregivers and they may have heightened vulnerability to many adverse consequences, non-adherence to prescription medications for mental health difficulties is not one of the factors that they may be vulnerable to. This is very useful to identify issues that do not appear to face caregivers, thus research amongst caregivers can focus on identifying the other challenges that they face and supporting them in overcoming these difficulties. Overall, the current findings clearly contribute to our understanding of the family burden/caregiving experience.

\section{Acknowledgements}

The World Mental Health (WMH) team received funding for the collection of the NCS-R data. Details of this can be viewed on any of the methodology publications. However, the data is now freely available and the current author had no role in any of the funded stages.

\section{Conflict of Interests}

The author declares no competing interests.

\section{Authors’ Contributions}

Manuscript preparation has been conducted solely by the named author.

\section{Ethical Approval and Consent}

A full report of the methods employed within the NCS-R can be found Kessler et al. (2004) [27]. The Human Subjects Committees of both Harvard Medical School (HMS) and the University of Michigan approved the recruitment, consent, and field procedures of the NCS-R [27]. These ethical guidelines are compliant with the Helsinki Declaration on ethical principles for medical research involving human subjects.

\section{REFERENCES}

[1] E. Sales, "Family Burden and Quality Of Life," Quality of Life Research, Vol. 12, No. 1, 2003, pp. 33-41. http://dx.doi.org/10.1023/A:1023513218433

[2] Carers UK, "What Is Caring?” 2012. http://www.carersuk.org/about-us/what-is-caring 
[3] S. Carratero, J. Garces, F. Rodenas and V. Sanjose, "The Informal Caregiver's Burden of Dependent People: Theory and Empirical Review,” Archives of Gerontology and Geriatrics, Vol. 49, No. 1, 2009, pp. 74-79.

http://dx.doi.org/10.1016/j.archger.2008.05.004

[4] E. W. Gonzalez, M. Polansky, C. F. Lippa, D. Walker and D. Feng, "Family Caregivers at Risk: Who Are They?" Issues in Mental Health Nursing, Vol. 32, No. 8, 2011, pp. 528-536. http://dx.doi.org/10.3109/01612840.2011.573123

[5] A. L. Neri, M. S. Yassuda, A. C. G. Fortes-Burgos, E. P. Mantovani, F. S. Arbex, S. V. DeSouza-Torres, M. R. Perracini and M. E. Guariento, "Relationships between Gender, Age, Family Conditions, Physical and Mental Health, and Social Isolation of Elderly Caregivers,” International Psychogeriatrics, Vol. 24, No. 3, 2012, pp. 472-483. http://dx.doi.org/10.1017/S1041610211001700

[6] S. Savage and S. Bailey, "The Impact of Caring on Caregivers' Mental Health: A Review of the Literature,” Australian Health Review, Vol. 27, No. 1, 2004, pp. 103-109. http://dx.doi.org/10.1071/AH042710111

[7] W. E. Haley, J. Y. Allen, J. S. Grant, O. J. Clay, M. Perkins and D. L. Roth, "Problems and Benefits Reported by Stroke Family Caregivers: Results from a Prospective Epidemiological Study,” Stroke, Vol. 40, No. 6, 2009, pp. 2129-2133. http://dx.doi.org/10.1161/STROKEAHA.108.545269

[8] M. J. Poulin, S. L. Brown, P. A. Ubel, D. M. Smith, A. Jankovic and K. M. Langa, "Does a Helping Hand Mean a Heavy Heart? Helping Behaviour and Well-Being among Spouse Caregivers," Psychology and Aging, Vol. 25, No. 1, 2010, pp. 108-117. http://dx.doi.org/10.1037/a0018064

[9] R. C. Talley and J. E. Crew, "Framing the Public Health of Caregiving," American Journal of Public Health, Vol. 97, No. 2, 2007, pp. 224-228.

http://dx.doi.org/10.2105/AJPH.2004.059337

[10] WHO (World Health Organisation), “Adherence to Long Term Therapies: Evidence for Action,” 2003. http://www.who.int/chp/knowledge/publications/adherenc e_full_report.pdf

[11] M. R. DiMatteo, K. B. Haskard-Zolnierek and L. R. Martin, "Improving Patient Adherence: A Three Factor Model to Guide Practice," Health Psychology Review, Vol. 6, No. 1, 2012, pp. 74-91. http://dx.doi.org/10.1080/17437199.2010.537592

[12] S. A. AlGhurair C. A. Hughes, S. H. Simpson and L. M. Guirguis, "A Systematic Review of Patient Self-Reported Barriers to Adherence to Antihypertensive Medications Using the World Health Organization Multidimensional Adherence Model," The Journal of Clinical Hypertension, Vol. 14, No. 12, 2012, pp. 877-886. http://dx.doi.org/10.1111/j.1751-7176.2012.00699.x

[13] S. Kripliano, X. Yao and R. B. Haynes, "Interventions to Enhance Medication Adherence in Chronic Medical Conditions: A Systematic Review,” Archives of Internal Medicine, Vol. 167, No. 6, 2007, pp. 540-550. http://dx.doi.org/10.1001/archinte.167.6.540

[14] R. J. Simpson, "Challenges for Improving Medication
Adherence," Journal of the American Medical Association, Vol. 296, No. 21, 2006, pp. 2614-2616. http://dx.doi.org/10.1001/jama.296.21.jed60074

[15] L. Osterberg and T. Blaschke, "Adherence to Medication," New England Journal of Medicine, Vol. 353, No. 5, 2005, pp. 487-497. http://dx.doi.org/10.1056/NEJMra050100

[16] V. Shahly, S. Chatterji, M. J. Gruber, A. Al-Hamzawi, J. Alonso, L. H. Andrade, M. C. Angermeyer, R. Bruffaerts, B. Bunting, J. M. Caldas-de Almeida, G. de Girolamo, P. de Jongo, S. Florescu, O. Gureje, J. M. Haro, H. R. Hinkov, C. Hu, E. G. Karam, J. P. Lepine, D. Levinson, M. E. Medina-Mora, J. Posada-Villa, N. A. Sampson, J. K. Trivedi, M. C. Viana and R. C. Kessler, "Cross-National Differences in the Prevalence and Correlates of Burden among Older Family Caregivers in the WHO World Mental Health (WMH) Surveys,” Psychological Medicine, Vol. 43, No. 4, 2013, pp. 865-879. http://dx.doi.org/10.1017/S0033291712001468

[17] J. Robison, R. Fortinsky, A. Kleppinger, N. Shugrue and M. Porter, "A Broader View of Family Caregiving: Effects of Caregiving and Caregiver Conditions on Depressive Symptoms, Health, Work, and Social Isolation," Journal of Gerontology: Social Sciences, Vol. 64, No. 6, 2009, pp. 788-798.

http://dx.doi.org/10.1093/geronb/gbp015

[18] W. H. Shrank, J. N. Liberman, M. A. Fischer, E. Kilabuk, C. Girdish, S. Cutrona, T. Breenan and N. K. Choudry, "Are Caregivers Adherent to Their Own Medications?" Journal of the American Pharmacists Association, Vol. 51, No. 4, 2011, pp. e53-e59.

[19] M. Pinquart and S. Sorensen, “Associations of Caregiver Stressors and Uplifts with Subjective Well-Being and Depressive Mood: A Meta-Analytic Comparison,” Aging and Mental Health, Vol. 8, No. 5, 2004, pp. 428-449.

[20] M. Pinquart and S. Sorensen, "Correlates of Physical Health of Informal Caregivers: A Meta-Analysis,” Journal of Gerontology: Social Sciences, Vol. 62, No. 2, 2007, pp. 126-137. http://dx.doi.org/10.1093/geronb/62.2.P126

[21] M. Y. Savundranayagam, R. J. V. Montgomery and K. Kosloski, "A Dimensional Analysis of Caregiver Burden among Spouses and Adult Children,” The Gerontologist, Vol. 51, No. 3, 2010, pp. 321-331. http://dx.doi.org/10.1093/geront/gnq102

[22] G. R. Smith, G. M. Williamson, L. S. Miller and R. Schulz, "Depression and Quality of Informal Care: A Longitudinal Investigation of Caregiving Stressors,” Psychology and Aging, Vol. 26, No. 3, 2011, pp. 584-591. http://dx.doi.org/10.1037/a0022263

[23] M. Pinquart and S. Sorensen, "Spouses, Adult Children and Children-in-Law as Caregivers of Older Adults: A Meta Analytic Comparison,” Psychology and Aging, Vol. 26, No. 1, 2011, pp. 1-14. http://dx.doi.org/10.1037/a0021863

[24] L. H. Hastrup, B. Van Den Berg and D. Gyrd-Hansen, "Do Informal Caregivers in Mental Illness Feel More Burdenened? A Comparative Study of Mental versus Somatic Illnesses," Scandanavian Journal of Public Health, Vol. 39, No. 6, 2011, pp. 598-607. http://dx.doi.org/10.1177/1403494811414247 
[25] B. K. Ahmedani, S. P. Kubiak, R. C. Kessler, R. DeGraaf, J. Alonso, R. Bruffaerts, Z. Zarkov, M. C. Viana, Y. Q. Huang, C. Hu, J. A. Posada-Villa, J. P. Lepine, M. C. Angermeyer, G. DeGirolamo, A. N. Karam, M. E. Medina-Mora, O. Gureje, F. Ferry, R. Sagar and J. C. Anthony, "Embarrassment When Illness Strikes a Close Relative: A World Mental Health Survey Consortium MultiSite Study,” Psychological Medicine, Vol. 43, No. 10, 2013, pp. 2191-2202.

[26] L. Magliano, A. Fiorillo, C. DeRosa, C. Malangoneand M. Maj, "The National Mental Health Project Working Group: Family Burden in Long Term Diseases: A Comparative Study in Schizophrenia vs Physical Disorders," Social Science and Medicine, Vol. 61, No. 2, 2005, pp. 313-322. http://dx.doi.org/10.1016/j.socscimed.2004.11.064

[27] R. C. Kessler, P. Berglund, W. T. Chiu, O. Demler, S. Heeringa, E. Hiripi, R. Jin, B. E. Pennell, E. E.Walters, A. Zaslavsky and H. Zheng, "The US National Comorbidity Survey Replication (NCS-R): Design and Field Procedures,” The International Journal of Methods in Psychia- tric Research, Vol. 13, No. 2, 2004, pp. 69-92. http://dx.doi.org/10.1002/mpr.167

[28] A. Bobinac, N. J. van Exel, F. F. Rutten and W. B. Brouwer, "Caring for and Caring about: Disentangling the Caregiver Effect and the Family Effect," Journal of Health Economics, Vol. 29, No. 4, 2010, pp. 549-556. http://dx.doi.org/10.1016/j.jhealeco.2010.05.003

[29] M. C. Garber, D. P. Nau, S. R. Erickson, J. E. Aikens and J. B. Lawrence, "The Concordance of Self-Report with Other Measures of Medication Adherence: A Summary of the Literature,” Medical Care, Vol. 42, No. 7, 2004, pp. 649-652. http://dx.doi.org/10.1097/01.mlr.0000129496.05898.02

[30] A. T. Woodward, K. M. Bullard, R. J. Taylor, L. M. Chatters, R. E. Baser and B. E. Perron, "Use of Complementary and Alternative Medicines for Mental and Substance Use Disorders: A Comparison of African Americans, black Carribeans, and Non-Hispanic Whites," Psychiatric Services, Vol. 60, No. 10, 2009, pp. 1342-1349. http://dx.doi.org/10.1176/appi.ps.60.10.1342

\author{
Abbreviations \\ NCS-R National Comorbidity Study-Replication; \\ DSM-IV Diagnostic and Statistical Manual of Mental \\ Disorders IV
}

